\title{
DHA Supplementation Attenuates MI-Induced LV Matrix Remodeling and Dysfunction in Mice
}

\author{
I. Habicht, ${ }^{1}$ G. Mohsen, ${ }^{2}$ L. Eichhorn, ${ }^{2}$ S. Frede, ${ }^{2}$ C. Weisheit, ${ }^{2}$ T. Hilbert $\mathbb{D},{ }^{2}$ H. Treede, ${ }^{3}$ \\ E. Güresir, ${ }^{4}$ O. Dewald, ${ }^{5}$ G. D. Duerr $\mathbb{1}^{3},{ }^{3}$ and M. Velten $\mathbb{1}^{2}$ \\ ${ }^{1}$ Department of Orthopaedics and Trauma Surgery, University Hospital Bonn, Germany \\ ${ }^{2}$ Department of Anesthesiology and Intensive Care Medicine, University Hospital Bonn, Germany \\ ${ }^{3}$ Department of Cardiac Surgery, University Hospital Bonn, Germany \\ ${ }^{4}$ Department of Neurosurgery, University Hospital Bonn, Germany \\ ${ }^{5}$ Department of Cardiac Surgery, University Medical Center Oldenburg, Germany
}

Correspondence should be addressed to G. D. Duerr; dduerr@uni-bonn.de and M. Velten; markus.velten@ukbonn.de

Received 2 February 2020; Revised 24 March 2020; Accepted 7 April 2020; Published 14 May 2020

Guest Editor: Lynette K. Rogers

Copyright (c) 2020 I. Habicht et al. This is an open access article distributed under the Creative Commons Attribution License, which permits unrestricted use, distribution, and reproduction in any medium, provided the original work is properly cited.

Objective. Myocardial ischemia and reperfusion (I/R) injury is associated with oxidative stress and inflammation, leading to scar development and malfunction. The marine omega-3 fatty acids ( $\omega-3 \mathrm{FA})$, eicosapentaenoic acid (EPA), and docosahexaenoic acid (DHA) are mediating cardioprotection and improving clinical outcomes in patients with heart disease. Therefore, we tested the hypothesis that docosahexaenoic acid (DHA) supplementation prior to LAD occlusion-induced myocardial injury (MI) confers cardioprotection in mice. Methods. C57BL/6N mice were placed on DHA or control diets (CD) beginning $7 \mathrm{~d}$ prior to 60 min LAD occlusion-induced MI or sham surgery. The expression of inflammatory mediators was measured via RT-qPCR. Besides FACS analysis for macrophage quantification and subtype evaluation, macrophage accumulation as well as collagen deposition was quantified in histological sections. Cardiac function was assessed using a pressure-volume catheter for up to $14 \mathrm{~d}$. Results. DHA supplementation significantly attenuated the induction of peroxisome proliferator-activated receptor- $\alpha$ (PPAR- $\alpha$ ) $(2.3 \pm 0.4 \mathrm{CD}$ vs. $1.4 \pm 0.3 \mathrm{DHA})$ after LAD occlusion. Furthermore, TNF- $\alpha$ ( $4.0 \pm 0.6 \mathrm{CD}$ vs. $1.5 \pm 0.2 \mathrm{DHA}), \mathrm{IL}-1 \beta(60.7 \pm 7.0$ $\mathrm{CD}$ vs. $11.6 \pm 1.9 \mathrm{DHA})$, and IL-10 (223.8 $\pm 62.1 \mathrm{CD}$ vs. $135.5 \pm 38.5 \mathrm{DHA}) \mathrm{mRNA}$ expression increase was diminished in DHA-supplemented mice after $72 \mathrm{~h}$ reperfusion. These changes were accompanied by a less prominent switch in $\alpha / \beta$ myosin heavy chain isoforms. Chemokine mRNA expression was stronger initiated (CCL2 $6 \mathrm{~h}: 32.8 \pm 11.5$ CD vs. $78.8 \pm$ 13.6 DHA) but terminated earlier (CCL2 $72 \mathrm{~h}: 39.5 \pm 7.8 \mathrm{CD}$ vs. $8.2 \pm 1.9$ DHA; CCL3 72 h: $794.3 \pm 270.9$ CD vs. $258.2 \pm$ 57.8 DHA) in DHA supplementation compared to CD mice after LAD occlusion. Correspondingly, DHA supplementation was associated with a stronger increase of predominantly alternatively activated Ly6C-positive macrophage phenotype, being associated with less collagen deposition and better LV function (EF $14 \mathrm{~d}$ : $17.6 \pm 2.6 \mathrm{CD}$ vs. $31.4 \pm 1.5 \mathrm{DHA}$ ). Conclusion. Our data indicate that DHA supplementation mediates cardioprotection from MI via modulation of the inflammatory response with timely and attenuated remodeling. DHA seems to attenuate MI-induced cardiomyocyte injury partly by transient PPAR- $\alpha$ downregulation, diminishing the need for antioxidant mechanisms including mitochondrial function, or $\alpha$ - to $\beta$-MHC isoform switch.

\section{Introduction}

Coronary heart disease $(\mathrm{CHD})$ is a significant health concern in the western world with increasing prevalence and the leading cause of death in Europe, accounting for $€ 60$ billion in health care costs annually [1]. Timely coronary reperfusion using either percutaneous coronary intervention (PCI) or thrombolytic therapy is the most effective strategy for limiting infarct size, preserving left-ventricular (LV) function, and therefore preventing myocardial injury and the development of heart failure [2]. Despite early onset therapies, in hospital mortality has risen up to $14 \%$ and productivity loss 
accounts for $38 \%$ of CHD-related health care costs [1]. Therefore, novel therapeutic approaches are required to reduce $\mathrm{MI}$ size, preserve $\mathrm{LV}$ function, and improve clinical outcomes after MI.

Although an early intervention reestablishing coronary perfusion is essential for myocardial salvage after MI, reperfusion itself triggers a further injury [3]. This so-called ische$\mathrm{mia} /$ reperfusion (I/R) injury is an inherent response to the restoration of blood flow involving numerous mechanisms including the increased generation of reactive oxygen species (ROS), acute calcium overload of cardiomyocytes, and opening of the mitochondrial permeability transition pore (MPTP), leading to uncoupled oxidative phosphorylation and thus contractile dysfunction. These insults further aggravate myocardial remodeling after MI, through increased generation of proinflammatory and proapoptotic molecules resulting in myocyte death, collagen deposition, and scar formation, exacerbating the development of heart failure $[4,5]$. In summary, reperfusion itself induces additional cardiac damage that is responsible for up to $50 \%$ of infarct size, making this cascade of events a viable target for therapeutic interventions [3]. Currently, there is no effective clinical therapy preventing the deleterious consequences of myocardial I/R injury. Therefore, attenuating $\mathrm{I} / \mathrm{R}$ injury is an important target for cardioprotection and a promising therapeutic approach to improve clinical outcomes after an acute MI.

Inflammation is pivotal for the development of heart failure, and an unrestricted inflammatory response is associated with worse prognosis after MI [6, 7]. Furthermore, excessive increases in inflammatory mediators, e.g., cytokines, have been shown to induce myocardial injury, including impaired cardiomyocyte contractility and excessive myocardial remodeling [8-11]. Myocardial reperfusion after ischemia generates an imbalance between reactive oxygen species (ROS) and the capacity of cells to defend against them, leading to increased ROS generation. The inducible transcription factor peroxisome proliferator-activated receptor- $\gamma$ (PPAR$\gamma$ ) regulates various cardiovascular processes and reduces I/R injury-induced cardiac inflammation and ROS generation [12]. Elevated ROS levels consume and surpass the antioxidant capacity of the injured myocardium, significantly contributing to oxidative stress generation and affecting protein function, resulting in myocardial damage with morphological and functional abnormalities [13]. In cardiac I/R injury, significant sources of ROS are inflammationinduced phagocyte-type NAD (P) H oxidase and mitochondrial metabolism-associated fatty acid oxidation $[14,15]$. Excessive ROS generation opens the mitochondrial permeability transition pore (MPTP) further contributing to myocardial injury and contractile dysfunction. Mitochondrial uncoupling proteins (UCP) have been shown to protect cardiomyocytes from ROS-induced cell death and heart failure. Furthermore, UCP overexpression has been reported as an adaptive mechanism against oxidative stress in various cardiac pathologies. ROS overproduction and oxidative stress play key roles for the development of cardiac injury, promoting complications of cardiac reperfusion [16]. Thus, preventing I/R injury-induced ROS generation is an important target for the development of novel strategies to preserve cardiac function after MI.

Polyunsaturated fatty acids (PUFAs) are a group of metabolic active lipid molecules. The marine omega- 3 fatty acids ( $\omega$-3 FA), eicosapentaenoic acid (EPA), and docosahexaenoic acid (DHA) are beneficial for health outcomes [17], mediating cardiovascular benefits in preclinical studies and improve clinical outcomes in patients with MI, potentially through modulation of inflammation and antioxidant effects [18, 19]. Long-lasting $\omega-3 \mathrm{FA}$ intake is reported to reduce mortality up to $45 \%$ and morbidity (myocardial infarction, arrhythmia) in adult patients with cardiovascular disease [20]. Consequently, supplementation is recommended for patients with prevalent CHD such as a recent MI [21, 22]. DHA is either obtained from diet but can also be synthesized from EPA $[23,24]$. Thus, various investigations used combinations of DHA and EPA to investigate $\omega-3$ FA effects on cardiac health. The OMEGA-REMODEL trial proved that highdose DHA/EPA supplementation beginning at the onset of MI improved LV function after 6 months [18]. However, underlying mechanisms, signaling pathways, and effectors of DHA/EPA-mediated prevention of I/R injury-induced cardiac dysfunction in acute $\mathrm{MI}$ remain to be revealed $[24,25]$. DHA/EPA modulate numerous receptors and decrease the generation of intracellular reactive oxygen species with a subsequent diminished activation of redoxsensitive transcription factors through its incorporation into cellular membranes. In addition to inflammatory resolution, DHA has numerous effects that include oxygen consumption, mitochondrial energy metabolism, contractile function, calcium signaling, and ROS generation, potentially protecting the cardiovascular system [26-28].

Previous attempts to translate cardioprotective strategies for $\mathrm{I} / \mathrm{R}$ injury from the experimental into the clinical setting have not been successful, potentially due to an incomplete understanding of the underlying molecular mechanisms including inflammation, oxidative stress, calcium overload, mitochondrial dysfunction, and different cell types affected [29]. However, most approaches targeted just one mechanism, but several of these mechanisms interact. Therefore, understanding these interactions and targeting multiple mechanisms are essential to prevent I/R injury-induced cardiac dysfunction. DHA and EPA interact with many mechanisms that are associated with the development of I/R injuryinduced cardiac dysfunction including inflammation, ROS generation, matrix remodeling, and mitochondrial metabolism [26]. Therefore, $\omega-3 \mathrm{FA}$ are promising therapeutics and understanding its interactions in myocardial I/R injury may help to reduce infarct size, prevent the development of LV dysfunction, and improve clinical outcomes after MI.

\section{Materials and Methods}

2.1. Animal Protocol. All animals were handled according to the animal protocol and to the EU Directive 2010/63/EU for animal research. Experimental procedures have been approved by the government animal care and use committee "Landesamt für Natur, Umwelt und Verbraucherschutz NRW" (50.203.2-BN 43, 28/01). 20-25g and 10-12 weeks 
old male C57BL/6 mice were purchased from Charles River (Sulzfeld, Germany). To limit transportation and social stress, mice were housed at our facility for at least 7 days prior to the experiments. Animals were placed in plastic cages filled with autoclaved bedding in a filtered flow cage rack on a 12hour light/dark cycle with free access to water and standard rodent chow. All mice were sacrificed by cervical dislocation at the end of the experiment.

2.2. Closed Chest Mouse Model of LAD Occlusion. Before surgery perioperative analgesia was performed using carprofen $5 \mathrm{mg} / \mathrm{kg}$ s.c. and Temgesic $0.1 \mathrm{mg} / \mathrm{kg}$ s.c. Anesthesia was then induced with $3 \%$ isoflurane (Forene ${ }^{\circledR}$, Abbott) and maintained with $0.8 \%$ isoflurane in $100 \% \mathrm{O}_{2}$. Left parasternal thoracotomy was performed for implantation of the ligature (8-0 Prolene suture, Ethicon, Norderstedt, Germany) around the left descending coronary artery (LAD). The suture ends were threaded through a sterile PE10 tube (Becton Dickinson, Franklin Lakes, NJ, USA), exteriorized through the thoracic wall, and stored subcutaneously [30]. After chest closure, cefuroxime suspension was injected i.p. (50 mg/kg, Zinacef; Bristol-Myers Squibb, Munich, Germany) for antibiotic prophylaxis. Mice were allowed to recover for 7-10 days from initial surgery intervention.

2.3. Induction of Myocardial Ischemia and Reperfusion (I/R). Myocardial ischemia was induced under the same analgesic and anesthetic measures as described above. The LAD ligature ends were connected to heavy metal picks, and LAD occlusion for $60 \mathrm{~min}$ was achieved by pulling the picks apart as described previously [30]. Myocardial ischemia was confirmed by visualization of ST segment elevation in EKG lead II of Einthoven. The hearts were reperfused after removal of the LAD ligature. Persistence of ST-segment elevation confirmed myocardial infarction. After reperfusion, the hearts were excised at different time points, dissected free from the atria and great vessels, and rinsed in ice-cold cardioplegic solution.

2.4. Experimental Groups and Protocols. To evaluate whether $\omega-3$ FA pretreatment associated mechanisms mediating cardioprotection for I/R injury-induced LV dysfunction, after implantation of the LAD ligature, $\mathrm{C} 57 \mathrm{BL} / 6 \mathrm{~N}$ mice were randomly distributed to receive either DHA or control diet (CD) beginning 7 days prior to I/R and for the duration of the experiment. DHA and control diets were identical with the exception of the composition of the $\omega$-3 FA, and 7 days of diet supplementation has shown to increase DHA concentrations and attenuate inflammation and oxidation in other pathologies [31-33]. Linoleic acid was used as a source for $\omega-6$ FA, and amounts were similar in CD and DHA diets. However, total $\omega-3$ FA contents were similar in control and DHA diets, but $37 \% \omega-3$ FA content in the DHA diet was DHA and the remaining half was linolenic acid from flaxseed oil, while in the control diet, the entire amount of $\omega$-3 FA was linolenic acid (Table 1).

A purified diet with higher linolenic acid concentrations that is metabolized to arachidonic acid was chosen to isolate
Table 1: Diet composition.

\begin{tabular}{lcc}
\hline PUFA & Control diet & DHA diet \\
\hline Linoleic $(18: 2)$ & $3.00 \mathrm{~g} / \mathrm{kg}$ & $2.9 \mathrm{~g} / \mathrm{kg}$ \\
Linolenic $(18: 3)$ & $0.7 \mathrm{~g} / \mathrm{kg}$ & $0.43 \mathrm{~g} / \mathrm{kg}$ \\
DHA $(22: 6)$ & $0.0 \mathrm{~g} / \mathrm{kg}$ & $0.26 \mathrm{~g} / \mathrm{kg}$ \\
\hline
\end{tabular}

the effects of preformed DHA supplementation from those of the precursor $\alpha$-linolenic acid and to avoid variability in standard chows [34].

2.4.1. In Vivo Functional Analysis Using Millar ${ }^{\circledR}$ PressureVolume Left Heart Catheter. Anesthetized mice (0.8\% isoflurane) were ventilated, and the jugular vein was cannulated with microenathane-033 tubing for hypertonic saline administration. After warming, the conductance catheter probe was advanced into the LV through the right carotid artery. Data collection was initiated after baseline stabilization. The Millar catheter uses conductance to determine relative volume units or "RVU." Once RVU's are measured, we then use a known volume of blood from the individual mouse using mock-up cylinders with known volumes to convert to a known volume [35]. Furthermore, inferior vena cava occlusion was used to measure the end-systolic pressure-volume relationship (ESPVR) and end-diastolic pressure-volume relationship (EDPVR), which are the index of ventricular filling pressures.

2.4.2. Immunohistochemistry. For immunohistochemistry, Vectastain Elite ABC kits and diaminobenzidine (AXXORA, Lörrach, Germany) were used. Cell density was described as cells $/ \mathrm{mm}^{2}$, as previously reported and evaluated by a histological technician blinded for group assignment [31-33]. For mouse-derived antibodies, the mouse-on-mouse (M.O.M) immunodetection kit (AXXORA) was used. MAC-2 rat anti-mouse antibody (clone 3/38) was used for macrophages (Cedarlane, Ontario, Canada).

2.4.3. Collagen Content. Excised hearts where fixated in $10 \%$ buffered zinc-formalin followed by paraffin embedding. $5 \mu \mathrm{m}$ sections from the level of the papillary muscle insertion were stained with hematoxylin and eosin (HE) or picrosirius red (SR), as previously described [36]. Quantitative analysis was accomplished by light microscopy with a video-image analyzer. Planimetric evaluation of collagen was performed on one section, including all four sites of the left ventricular myocardium, each at 100x magnification. Data was given as a percentage of the total left ventricular area. Collagenstained vessels and pericardium were excluded.

2.4.4. Flow Cytometry Analyses (FACS). LV tissue was homogenized, inflammatory cells were labeled with fluorescence $\mathrm{AB}$, and single-cell suspensions from the heart were generated as previously described [37]. The following antibodies from Thermo Fisher and BioLegend (San Diego, CA, USA) were used: CD45 (AFS98), F4/80 (BM-8), Gr1 (RB68C5), CD11c (N418), CD4 (RM4-5), CD8 (53-6.4), and B220 (RA3-6B2). In addition, the Annexin V-FITC Apoptosis Detection Kit (Thermo Fisher) was used according to the manufacturer's protocol. We performed flow cytometry on a 
FACS-Canto II, LSR II, and Fortessa (BD Biosciences, Heidelberg, D), and data was analyzed with FlowJo software (TreeStar, Ashland, OR, USA).

2.4.5. Gene Expression Analysis. Gene expression was measured on a transcriptional level using Taqman ${ }^{\circledR}$ real-time quantitative RT-qPCR. FAM-TAMRA-linked customized primers were used in an ABI Prism 7900HT Sequence Detection System and SDS2.4 software (Applied Biosystems/Life Technologies, Karlsruhe, Germany). The mRNA expression was related to shams and GAPDH using the comparative $\Delta \Delta$ Ct-method [38].

2.4.6. Statistical Analysis. Normal distribution was tested, and data was presented as mean \pm SEM. Statistical analysis was performed by two-way ANOVA and Bonferroni post hoc testing (PRISM 5.1; GraphPad, La Jolla, CA, USA). $P<$ 0.05 was considered statistically significant.

\section{Results}

3.1. DHA Supplementation Attenuates MI-Induced Systolic and Diastolic Dysfunction. To evaluate whether DHA pretreatment attenuates the development of MI-induced LV dysfunction, we examined the pressure-volume parameters of LV function in CD- and DHA-pretreated mice 14 days after $60 \mathrm{~min}$ of LAD occlusion-induced myocardial infarction (MI). Left ventricular end-systolic pressure (LVESP) was not different between sham or MI groups, regardless of DHA or CD pretreatment (Figure 1(a)). However, left ventricular end-diastolic pressure (LVEDP) significantly increased in $\mathrm{CD}$ mice 14 days after MI, compared to respective sham. Nevertheless, LVEDP remained at sham levels in DHA-supplemented mice and was significantly lower compared to CD mice 14 days after MI (Figure 1(b)). Mice with surgical MI had poorer ejection fraction (EF), but DHA pretreatment improved $\mathrm{EF}$ in the MI group compared to $\mathrm{CD}$ (Figure $1(\mathrm{c}))$. Peak pressure decline $\left(\mathrm{dP} / \mathrm{dt}_{\text {min }}\right)$ was reduced in CD-fed mice compared to sham 14 days after MI. However, $\mathrm{dP} / \mathrm{dt}_{\min }$ was sustained at sham levels in DHAsupplemented mice 14 days after MI and was significantly higher compared to $\mathrm{CD}$ mice at the same time point (Figure 1(d)). No differences were observed in peak pressure rise $\left(\mathrm{dP} / \mathrm{dt}_{\max }\right) 14$ days after MI in CD- or DHAsupplemented mice compared to respective sham (Figure 1(e)). Isovolumic relaxation constant (Tau) increased in CD mice compared to sham 14 days after MI. However, Tau remained at sham levels in DHA-supplemented mice and was significantly lower compared to $\mathrm{CD}$ mice 14 days after MI (Figure 1(f)). Two-way ANOVA indicated effects of DHA supplementation, MI, and an interaction between $\mathrm{EF}$ and Tau. Furthermore, statistical analyses indicated independent effects of DHA supplementation and MI on LVEDP and $\mathrm{dP} / \mathrm{dt}_{\text {min }}$.

3.2. DHA Supplementation Modulates Cytokine Expression after MI. Sham procedure did not induce a sustained cytokine expression 7 days after LAD ligature implantation compared to native animals. However, the murine myocardium exhibited a marked mRNA upregulation of inflammatory cytokines after 60 min LAD occlusion compared to sham mice. TNF- $\alpha$ mRNA expression was increased in CD mice $6 \mathrm{~h}$ and $24 \mathrm{~h}$ after MI, while DHA-supplemented mice exhibited just a brief induction $6 \mathrm{~h}$ after MI compared to respective sham. Furthermore, MI-induced TNF- $\alpha$ mRNA expression increase was significantly lower in DHA-supplemented mice $6 \mathrm{~h}$ and $72 \mathrm{~h}$ after MI compared to CD groups (Figure 2(a)). Furthermore, IL-1 $\beta$ mRNA expression was increased in $\mathrm{CD}$ mice $24 \mathrm{~h}$ and $72 \mathrm{~h}$ after MI compared to respective sham, while MIinduced IL-1 $\beta$ mRNA expression occurred in DHAsupplemented mice already at $6 \mathrm{~h}$ and was terminated after $24 \mathrm{~h}$. Furthermore, IL- $1 \beta$ mRNA expression was significantly greater in $\mathrm{CD}$ mice $72 \mathrm{~h}$ after MI compared to DHA-supplemented mice (Figure 2(b)). IL-10 mRNA was upregulated $72 \mathrm{~h}$ after $\mathrm{MI}$ in both $\mathrm{CD}$ - and DHAsupplemented mice. However, in mice with surgical MI, the DHA pretreatment was associated with a lower IL10 expression than CD $72 \mathrm{~h}$ after MI (Figure 2(c)). MIinduced cytokine mRNA expression demonstrated a similar pattern in DHA-supplemented mice; however, induction occurred earlier, levels were lower, and increase was terminated sooner compared to respective $\mathrm{CD}$ mice (Figures 2(a)-2(c)). Two-way ANOVA indicated independent effects of DHA supplementation and MI on TNF- $\alpha$ mRNA expression and an effect of MI on IL-1 $\beta$ and IL-10 expressions.

3.3. DHA Supplementation Modifies Inflammatory Response after MI. Data shown in Figure 3 demonstrate an effect of DHA supplementation on MI-induced inflammation. CCL2 chemokine expression was increased in CD mice $6 \mathrm{~h}, 24 \mathrm{~h}$, and $72 \mathrm{~h}$ after MI, while DHA-supplemented mice only exhibited CCL2 mRNA increases at $6 \mathrm{~h}$ and $24 \mathrm{~h}$ after MI compared to respective sham. However, CCL2 mRNA induction was significantly greater in DHA-supplemented mice $6 \mathrm{~h}$ after MI but terminated earlier compared to $\mathrm{CD}$ animals (Figure 3(a)). Furthermore, CCL3 mRNA expression was increased in $\mathrm{CD}$ mice compared to respective sham and DHA-supplemented mice $72 \mathrm{~h}$ after MI, while remained unchanged in DHA-supplemented mice compared to sham (Figure 3(b)). Fluorescence-activated cell sorting (FACS) analysis revealed greater increases in cardiac neutrophil and macrophage populations in DHA-supplemented mice compared to the CD group $3 \mathrm{~d}$ after MI (Figures 3(c) and 3(d)). Most importantly, cardiac macrophage population shifted from a more proinflammatory $\mathrm{Ly} 6 \mathrm{C}^{+}$to a more antiinflammatory and proremodeling $\mathrm{Ly}^{-} \mathrm{C}^{-}$phenotype in DHA supplemented compared to the $\mathrm{CD}$ group (Figures 3(e) and 3(f)).

In accordance with FACS analyses, MAC-2-stained histological sections revealed a large macrophage accumulation 7 days after I/R injury in both CD- and DHA-supplemented groups. However, DHA-supplemented mice showed a significantly greater infiltration of MAC-2-positive cells compared to $\mathrm{CD}$-fed mice 7 days after I/R injury (Figures 3(g)-3(i)). Two-way ANOVA revealed effects of MI and an interaction between DHA supplementation and LAD occlusion on CCL2 and CCL3 mRNA expressions. 


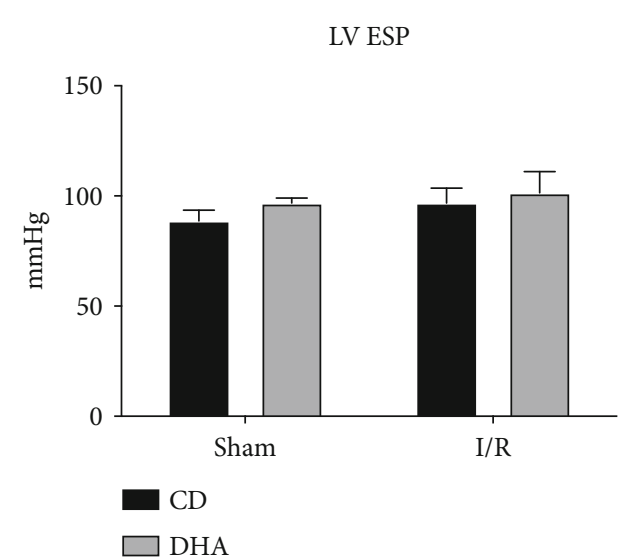

(a)

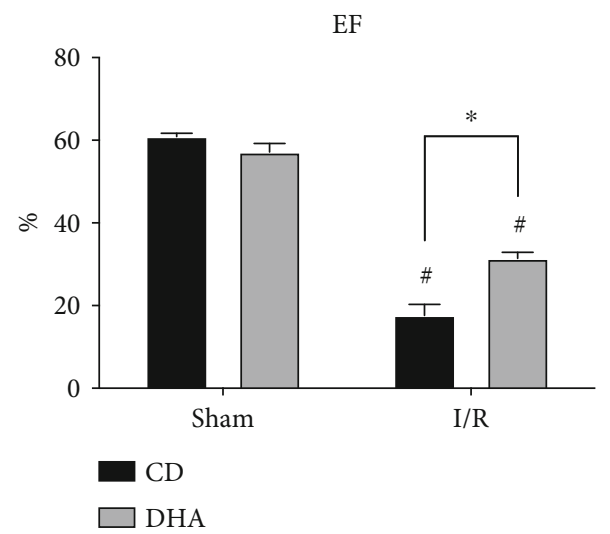

(c)

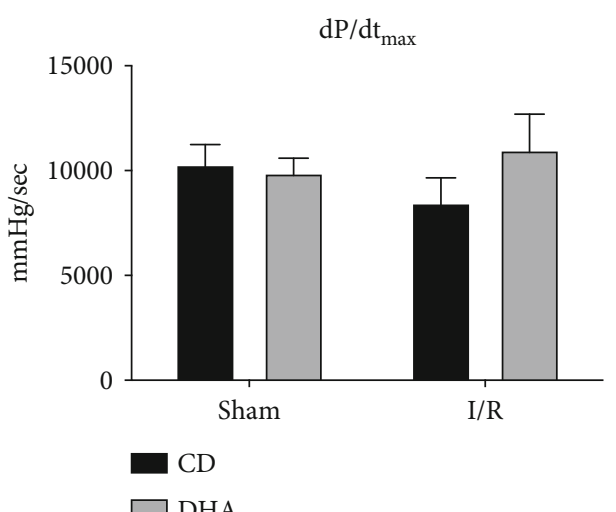

(e)

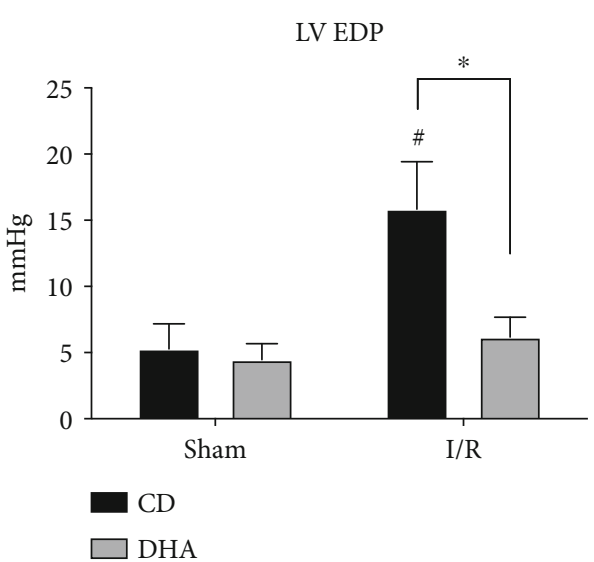

(b)

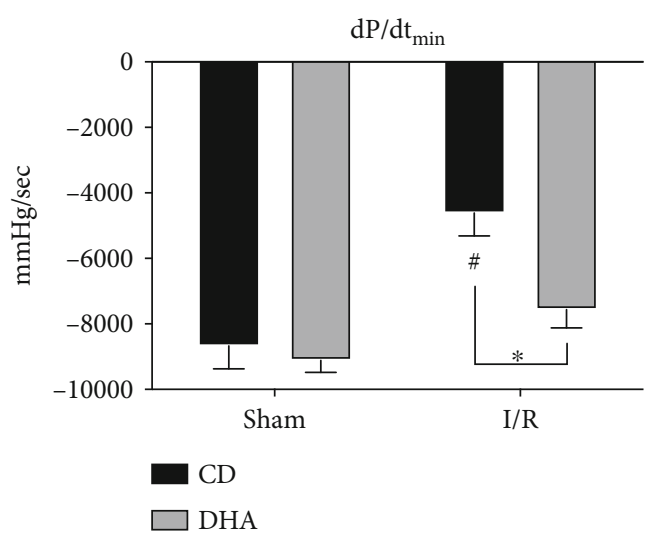

(d)

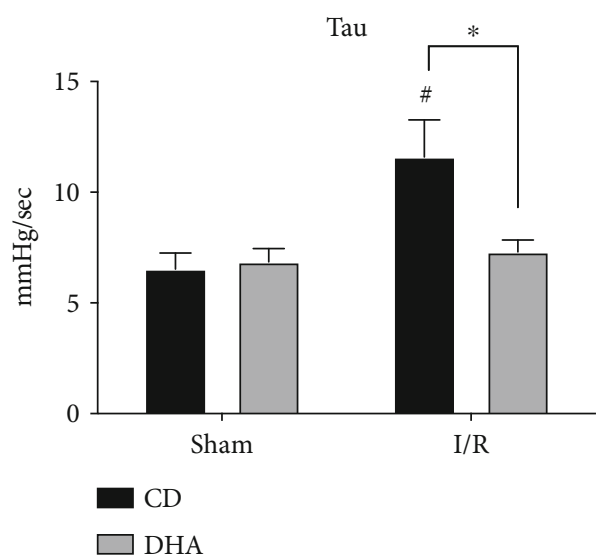

(f)

FiguRE 1: Improved cardiac function in DHA-supplemented mice after MI: functional parameters of (a) left ventricular end-systolic pressure (LVESP), (b) left ventricular end-diastolic pressure (LVEDP), (c) ejection fraction (EF), (d) peak pressure decline (dP/dt min $),(e)$ peak pressure rise $\left(\mathrm{dP} / \mathrm{dt}_{\max }\right)$, and (f) isovolumic relaxation constant (Tau), were analyzed $14 \mathrm{~d}$ after sham or MI in CD- or DHA-supplemented mice. $n=8$ mice per group ${ }^{*} P<0.05$.

3.4. DHA Supplementation Modifies Collagen Expression and Reduces LV Scar Formation after MI. TGF- $\beta$ mRNA was increased in both CD- and DHA-supplemented groups $24 \mathrm{~h}$ and $72 \mathrm{~h}$ after MI (Figure 4(a)). Collagen I and III mRNA expressions were also increased in both groups $72 \mathrm{~h}$ after MI compared to respective sham. However, collagen I
mRNA expression was significantly lower in DHAsupplemented mice compared to the $\mathrm{CD}$ group (Figures 4(b) and 4(c)). Furthermore, analyses of picrosirius red-stained histological sections revealed less collagen deposition in DHA supplemented compared to CD mice $14 \mathrm{~d}$ after MI (Figures 4(d) and 4(e)). Two-way ANOVA indicated the 
TNF- $\alpha$

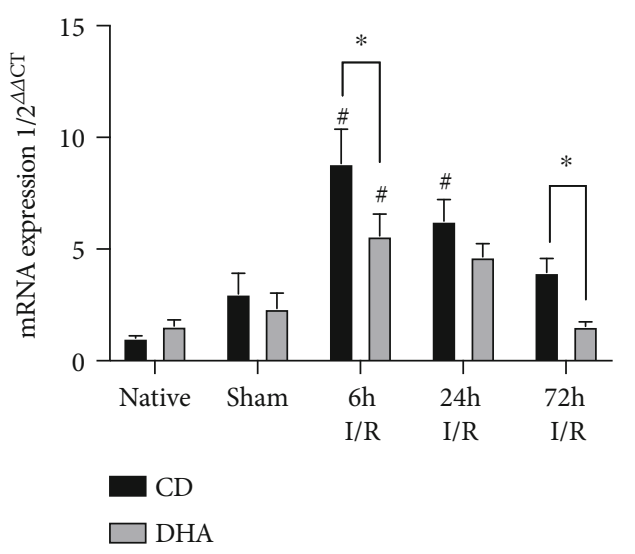

(a)
IL-1 $\beta$

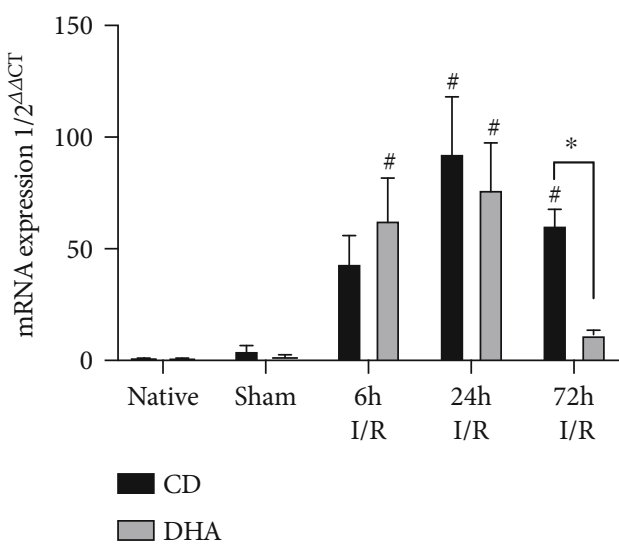

(b)

IL-10

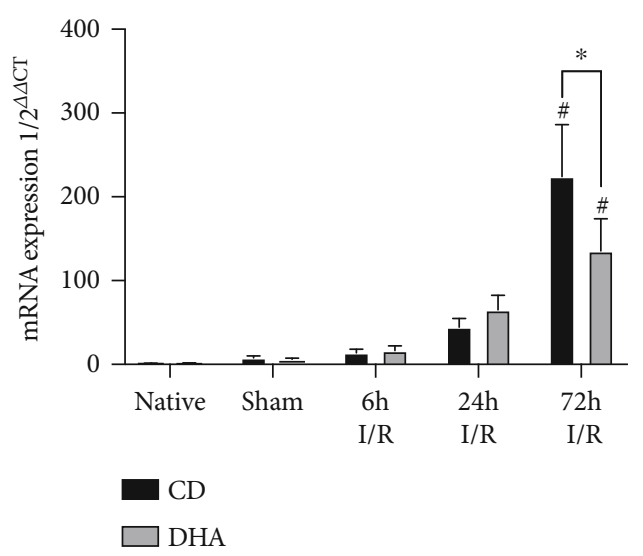

(c)

FIGURE 2: mRNA expression profile of inflammatory mediators. (a) TNF- $\alpha$, (b) IL- $1 \beta$, and (c) IL-10 mRNA expressions were analyzed in the murine myocardium of native, sham, and MI-exposed mice that were CD or DHA supplemented. $n=7$ mice per group, ${ }^{*} P<0.05$.

effects of MI on TGF- $\beta$, collagen I, and collagen III mRNA expressions and an interaction of MI with DHA supplementation on collagen I expression.

3.5. Myocardial Adaptation Mechanisms toward Ischemic Injury in DHA-Supplemented Mice. $\alpha$-Myosin heavy chain (MHC) mRNA expressions were decreased in both CDand DHA-supplemented mice $6 \mathrm{~h}$ after MI. However, $\alpha$ MHC mRNA expression returned to sham levels in DHAsupplemented mice, while remained lower in CD mice compared to DHA supplemented and respective sham $72 \mathrm{~h}$ after MI (Figure 5(a)). Furthermore, $\beta$-MHC expression was significantly increased in CD mice $24 \mathrm{~h}$ and $72 \mathrm{~h}$ after I/R injury, while DHA-supplemented mice only exhibited a transient increase in $\beta$-MHC expression $24 \mathrm{~h}$ after MI compared to respective sham. Most notably, $\beta$-MHC expression was significantly greater in CD compared to DHA-supplemented mice $24 \mathrm{~h}$ after MI (Figure 5(b)). Glutathione peroxidase 1 (GPx1) mRNA expressions were increased in both CD- and DHA-supplemented mice $24 \mathrm{~h}$ and $72 \mathrm{~h}$ after MI. However, GPx1 mRNA induction was also significantly greater in CD compared to DHA-supplemented mice $72 \mathrm{~h}$ after MI
(Figure 5(c)). Heme oxygenase 1 (HOX-1) mRNA expression increased in CD mice $72 \mathrm{~h}$ after MI compared to DHA supplemented and respective sham. Furthermore, HOX-1 remained at sham levels in DHA-supplemented mice. Twoway ANOVA indicated the effects of MI on $\alpha$-MHC, $\beta$ MHC, GPx1, and HMOX-1 mRNA expressions. However, there were independent effects of DHA supplementation on $\beta$-MHC and HMOX-1 and also an interaction of MI and DHA supplementation on $\beta$-MHC, GPx1, and HMOX-1 mRNA expressions.

3.6. DHA Preconditioning Impacts mRNA Expression of Enzymes Involved in Fatty Acid Metabolism. Peroxisome proliferator-activated receptor alpha (PPAR- $\alpha$ ) mRNA expression was lower in DHA-supplemented mice $6 \mathrm{~h}$ after MI compared to respective sham. In opposition, PPAR- $\alpha$ mRNA expression increased in CD mice $72 \mathrm{~h}$ after MI compared to DHA-supplemented and respective sham mice (Figure 6(a)). Mitochondrial uncoupling protein 3 (UCP 3) mRNA expression was increased in DHA-supplemented native and sham compared to $\mathrm{CD}$ mice. However, UCP 3 mRNA expression decreased in DHA supplemented, while 

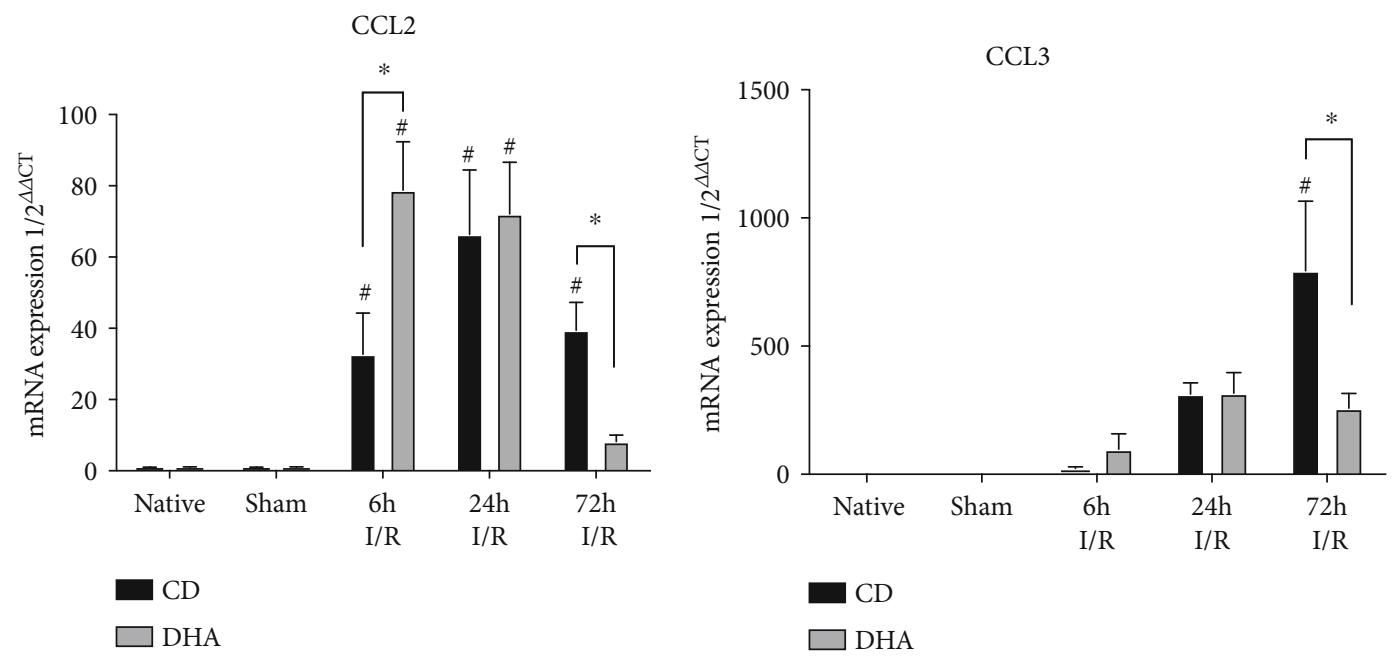

(a)

(b)

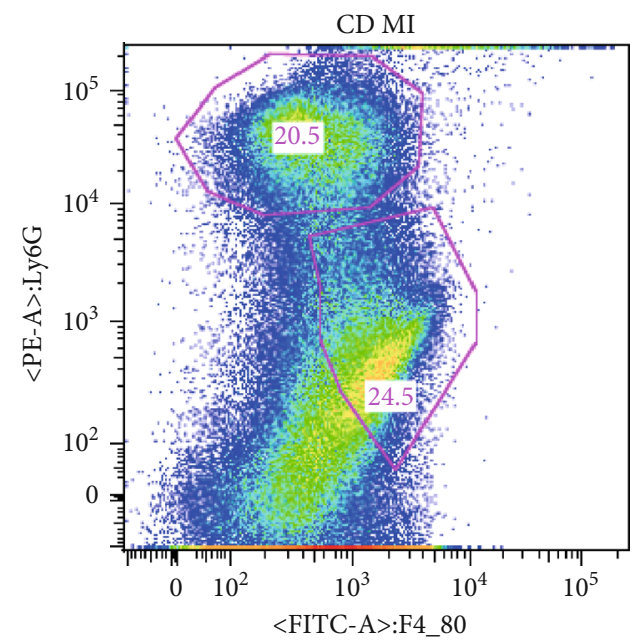

(c)

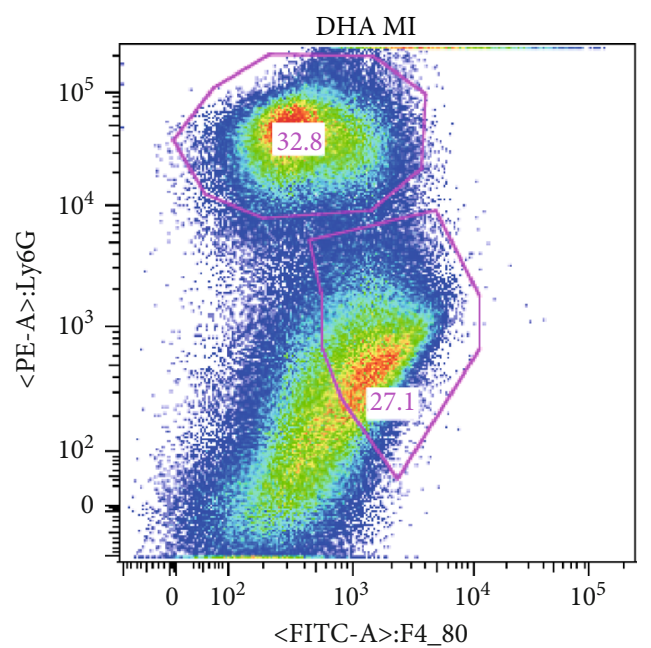

(d)

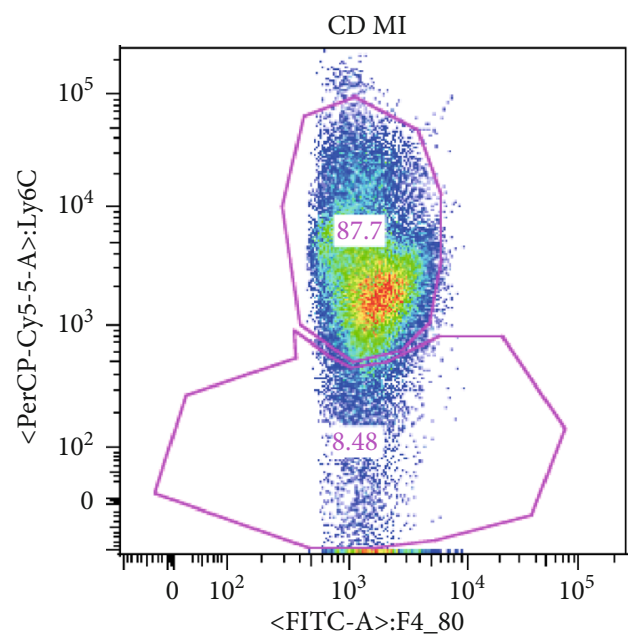

(e)

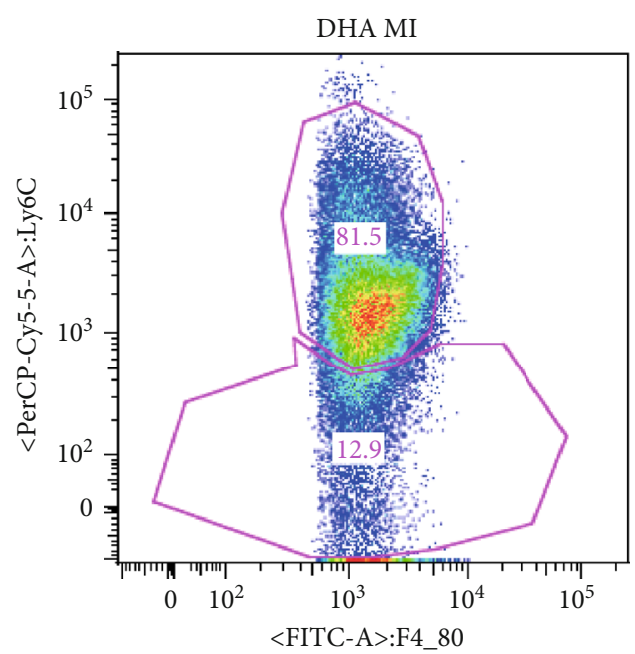

(f)

Figure 3: Continued. 
CD MI

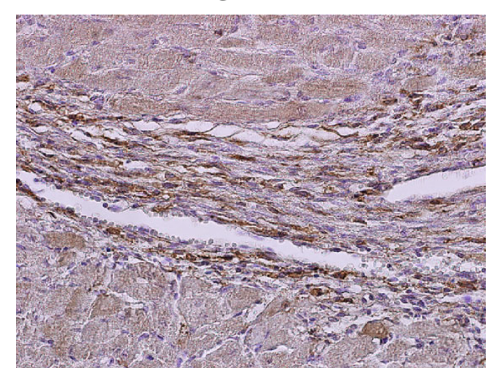

(g)

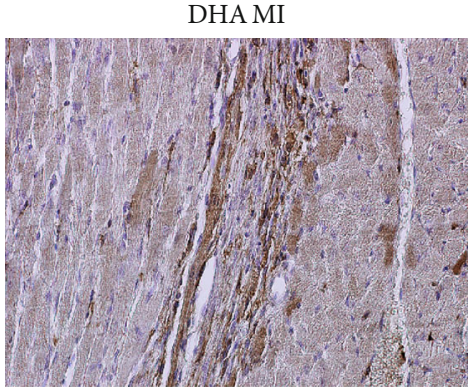

(h)

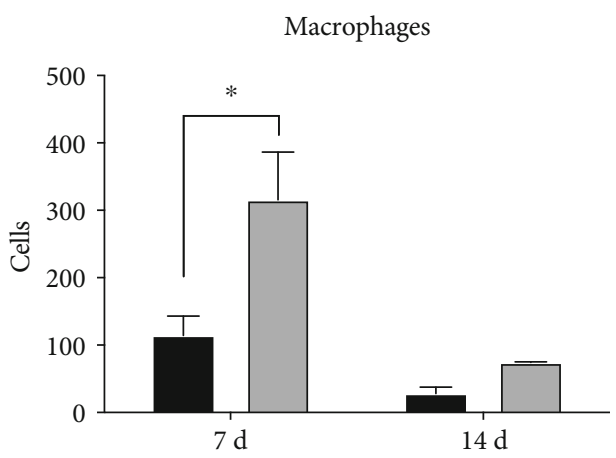

(i)

FIGURE 3: In mice with surgical MI, the DHA pretreatment was associated with a different inflammation pattern compared to the CD group. Cardiac (a) CCL2 and (b) CCL3 chemokine mRNA expressions were analyzed in the murine myocardium of native, sham, and MI-exposed mice that were CD or DHA supplemented. FACS analyses of cardiac neutrophil and macrophage populations in (c) CD or (d) DHA and phenotyping of macrophages in (e) CD- or (f) DHA-supplemented mice $3 \mathrm{~d}$ after MI. MAC-2 staining of representative histological left ventricular sections of cardiac macrophages in (g) CD- or (h) DHA-supplemented mice $7 \mathrm{~d}$ after MI and quantification (i) $n=7$ mice per group, ${ }^{*} P<0.05$.

increased in $\mathrm{CD}$ mice $6 \mathrm{~h}$ after $\mathrm{MI}$ compared to respective sham and DHA-supplemented mice. $24 \mathrm{~h}$ after MI UCP 3 mRNA expression was still reduced in DHA-supplemented mice, while returned to sham in $\mathrm{CD}$ groups with no difference between CD- and DHA-supplemented mice at this time point. However, UCP 3 mRNA expression increased in DHA-supplemented mice, while remained decreased in CD with a similar expression pattern compared to respective sham $72 \mathrm{~h}$ after MI (Figure 6(b)).

\section{Discussion}

The present study shows for the first time that modulation of the inflammatory response and adapted energy metabolism may play a role in the beneficial effect of DHA pretreatment on reperfused MI. Various studies investigating $\omega-3$ FA effects on cardiac health report positive effects using either DHA, EPA, or combinations since DHA is retroconverted to EPA, especially at higher concentrations as used in our investigation $[22,24,39,40]$. The present study used diets with similar omega-6 FA content and higher preformed DHA, but not EPA in DHA diet, in order to decrease confounding by individual and rate-limiting differences in long-chain polyunsaturated fatty acid metabolism [41]. Furthermore, the herein used concentration has been shown to increase DHA serum and tissue concentrations [31, 42], which was beneficial in pulmonary and neurological diseases in rodents $[32,33]$. Male mice were chosen to eliminate the complex cardioprotective effects that have been reported for all estrogen receptor subtypes against I/R injury, and a purified diet was chosen as the basis for both diets to avoid variability in standard chows [43].

The observed LV dysfunction in CD mice after reperfused $\mathrm{MI}$ is in accordance with previous studies from our groups and others [44-48]. However, in the present study, DHA supplementation beginning 7 days prior to $\mathrm{MI}$ resulted in sustained systolic and diastolic LV function that was characterized by lower end-diastolic pressure (EDP), greater ejection fraction $(\mathrm{EF})$, and reduced isovolumetric relaxation (Tau) $14 \mathrm{~d}$ after 60 min LAD occlusion compared to $\mathrm{CD}$-fed mice, with no difference in end-systolic blood pressures. These data suggest that DHA pretreatment has physiological consequences on the development of MIinduced LV dysfunction, preserving cardiac function in mice. The observed DHA-induced attenuation of MIinduced LV dysfunction adds to cardioprotective effects of other omega-3 FA in a Langendorff perfusion model reporting that an intravenous bolus of EPA: DHA 6: 1 protects against myocardial ischemia-reperfusion-induced injury [23]. Furthermore, preserved LV function in DHApretreated mice 14 days after $\mathrm{MI}$ is in line with the clinical data from the OMEGA-REMODEL trial, demonstrating that in humans, the combination of DHA and EPA $\omega-3$ FA ethyl ester supplementation beginning after the onset 


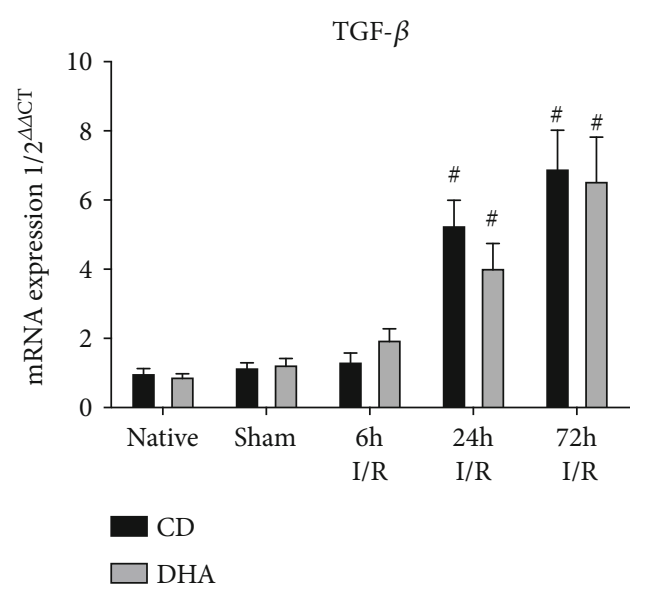

(a)

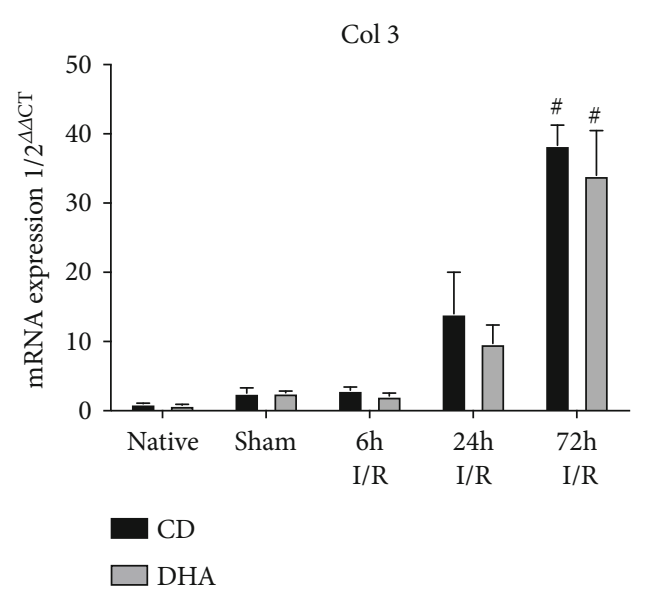

(c)

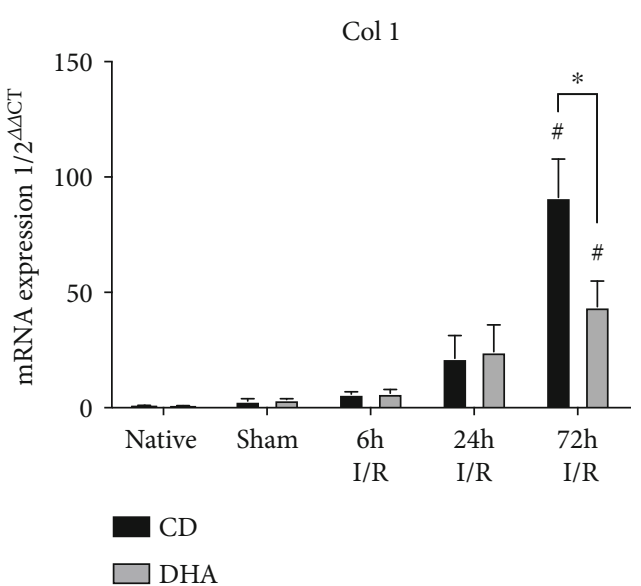

(b)

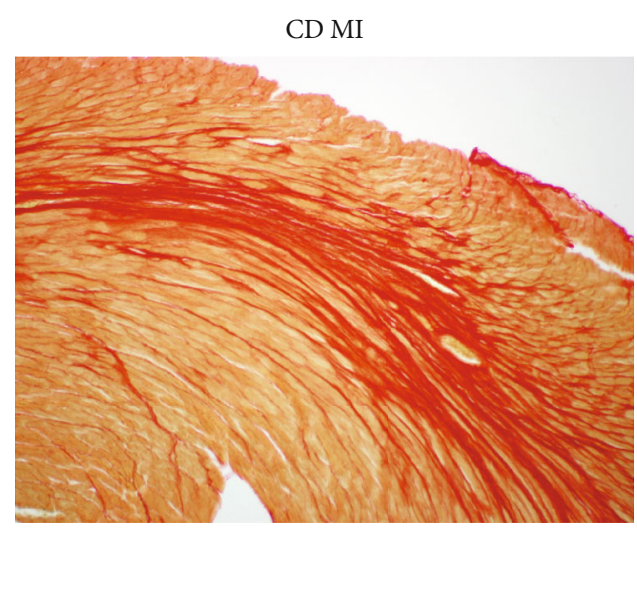

(d)

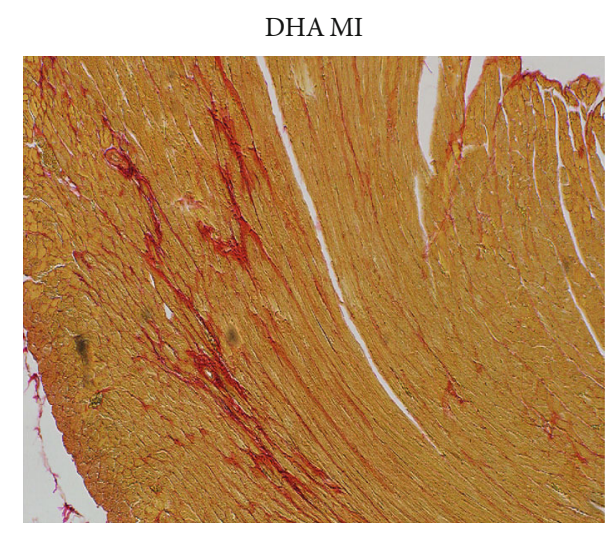

(e)

FIGURE 4: DHA supplementation modifies MI-induced myocardial remodeling: (a) TGF- $\beta$, (b) collagen I, and (c) collagen III mRNA expressions were analyzed in the murine myocardium of native, sham, and MI-exposed mice that were CD or DHA supplemented. $n=7$ mice per group, ${ }^{*} P<0.05$. Representative picrosirius red-stained histological sections from (d) CD- and (e) DHA-supplemented mice $14 \mathrm{~d}$ after I/R.

of STEMI improved LV function after 6 months. In summary, the preserved LV function in DHA-pretreated mice after reperfused MI is corroborated by the current clinical and experimental literature and suggests that DHA pre- treatment attenuates I/R injury-induced cardiac dysfunction in mice. Our study goes beyond this to investigate molecular mechanisms of omega-3 FA-induced cardioprotection following ischemia/reperfusion injury. 
$\alpha-\mathrm{MHC}$

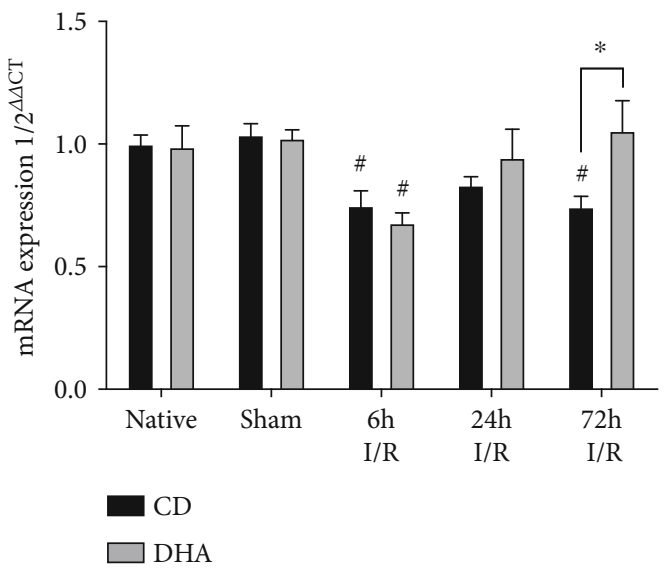

(a)

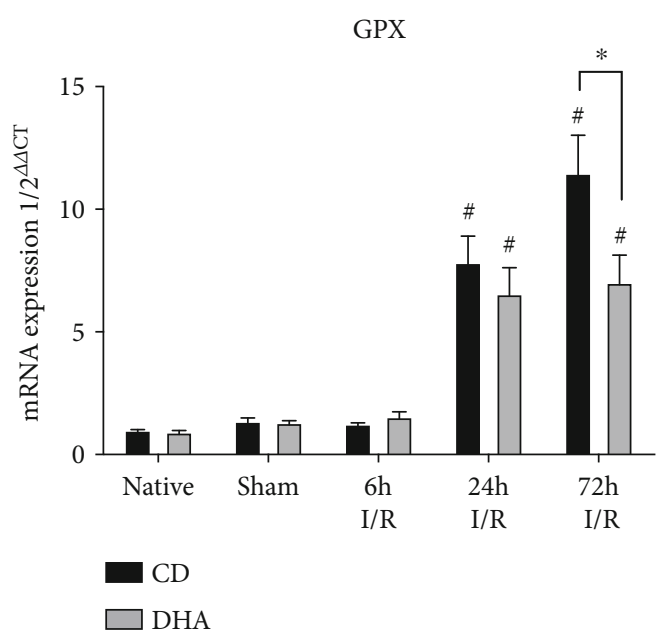

(c)

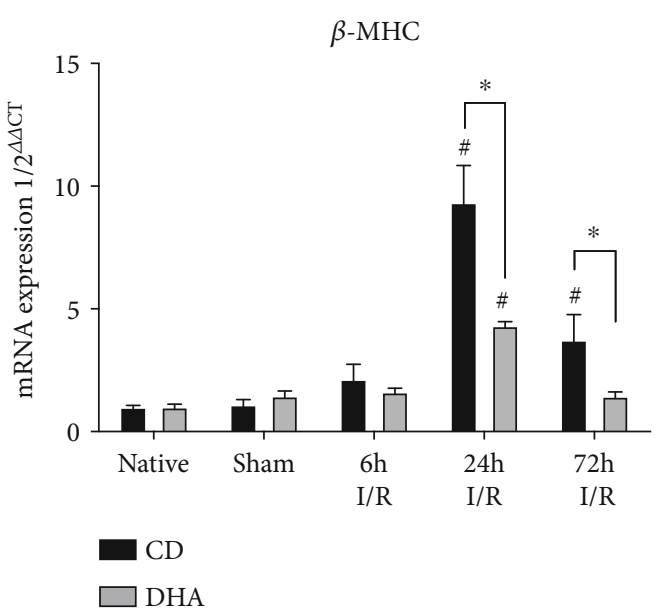

(b)

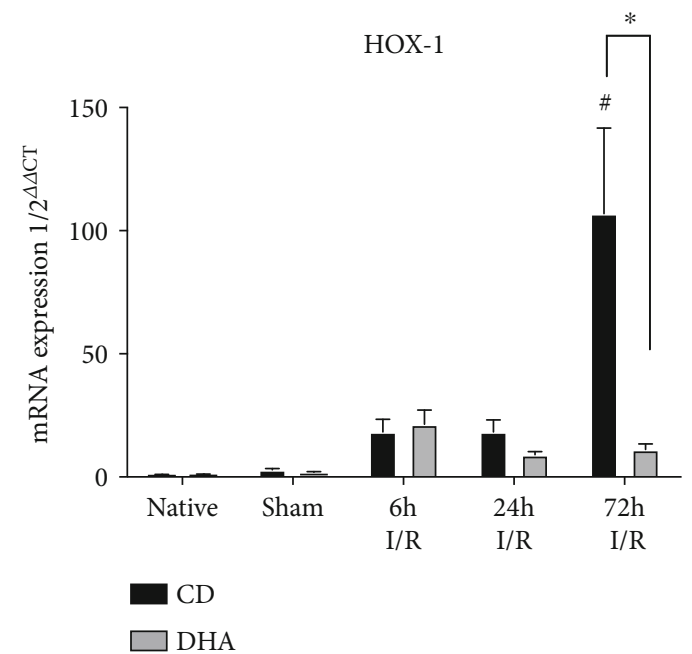

(d)

Figure 5: DHA-related cardiomyocyte adaptation after MI. MHC switch and induction of oxidative enzymes: myocardial (a) $\alpha$-MHC, (b) $\beta$ MHC, (c) GPX, and (d) HOX mRNA expressions were analyzed in the murine myocardium of native, sham, and MI-exposed mice that were CD or DHA supplemented. $n=7$ mice per group, ${ }^{*} P<0.05$.

Even though $\omega$-3 FA effects have been heavily studied in the context of MI, little is known about the beneficial metabolic and anti-inflammatory mechanisms that decrease the risk of heart failure associated with worse prognosis after MI if unrestricted. Various studies show the therapeutic potential of attenuating cardiac disease development via modulating the inflammatory response to various insults $[8$, $11,48-50]$.

In our study, DHA pretreatment was associated with an attenuation of cytokine expression. Furthermore, DHA leads to earlier and stronger initiation, but prompter termination of macrophage chemoattractant CCL2 expression. This data suggests that DHA treatment results in restricted inflammation, potentially attenuating remodeling in reperfused MI.

This inflammatory stimulus is also followed by an increased macrophage infiltration in DHA-treated mice $7 \mathrm{~d}$ after MI, returning to baseline levels after $14 \mathrm{~d}$. This strong but timely restricted inflammation in DHA-treated mice corroborates our hypothesis of timely and therefore attenuated remodeling. Accordingly, DHA treatment leads to less collagen deposition, resulting in smaller infarct sizes after reperfused MI. In this regard, we found that the peak of macrophages in DHA mice after $7 \mathrm{~d}$ consisted mainly of alternatively activated Ly6C-positive macrophage phenotype, being accompanied by less collagen deposition and better LV function in DHA-pretreated mice after $14 \mathrm{~d}$. In summary, this data suggests that a stronger remodeling stimulus leads to a more rapid and compacted scar formation and thus smaller infarct size in DHA-supplemented mice. Therefore, the beneficial effect of DHA may depend on modulation of the inflammatory response initiated by MI.

The expression of the myosin heavy chain (MHC) subunits is developmentally regulated and inappropriate expression associated with cardiomyopathies [51, 52]. Furthermore, heart failure is characterized by numerous molecular changes in contractile pathways including a switch from $\alpha$ - to $\beta$ MHC isoform [52-54]. $\beta$-MHC is characterized by lower ATP consumption and therefore higher efficiency, 


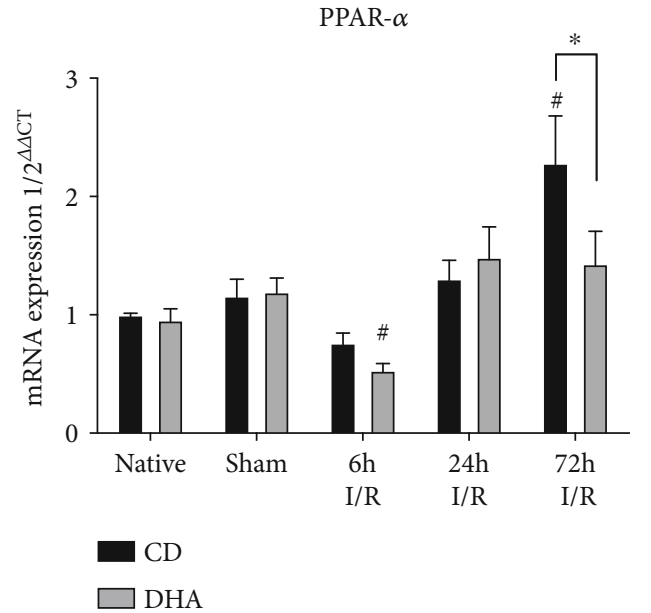

(a)

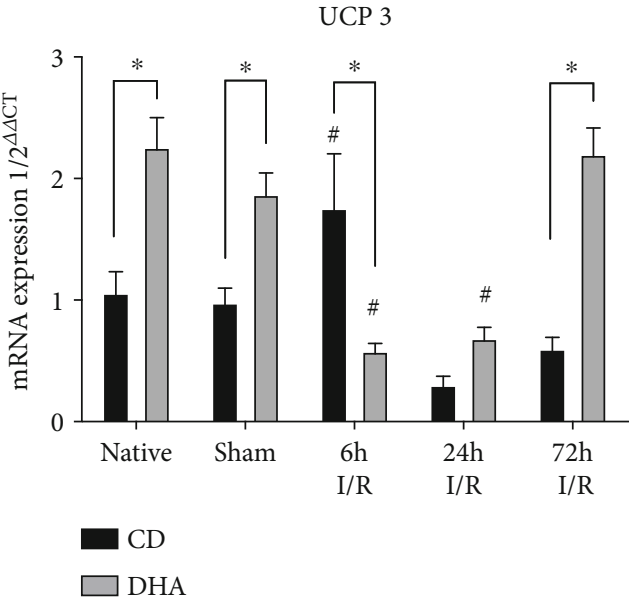

(b)

FIgURE 6: DHA pretreatment attenuates PPAR expression and enhances uncoupling protein expression post-MI; both are cardioprotective. (a) Peroxisome proliferator-activated receptor alpha (PPAR- $\alpha$ ) and (b) mitochondrial uncoupling protein 3 (UCP 3 ) mRNA expressions were analyzed in the murine myocardium of native, sham, and MI-exposed mice that were CD or DHA supplemented. $n=7$ mice per group, ${ }^{*} P<0.05$.

potentially being advantageous and implying that the $\alpha$ - to $\beta$-MHC shift may be an adaptive response to myocardial injury $[44,48]$.

In our study, $\alpha$-MHC mRNA expression showed a transient decrease after MI in both CD- and DHA-pretreated mice, indicative of favorable molecular changes in both groups (Figure 5(a)). Further, a significant increase in $\beta$ MHC expression was seen in both CD- and DHAsupplemented mice after $24 \mathrm{~h}$. Interestingly, $\beta$-MHC expression was significantly greater in CD compared to DHApretreated mice $24 \mathrm{~h}$ after MI, indicative of a lesser need for cardiomyocyte adaptation after DHA treatment (Figure 5(b)). Thus, the lower $\beta$-MHC mRNA upregulation in DHA-pretreated mice may be indicative of a cardioprotective mechanism possibly mediated through improved energy supply or altered metabolism.

Another important mechanism protecting cardiomyocyte adaption against myocardial injury consists of the reduction of oxidative stress, which modulates inflammatory response $[55,56]$. Glutathione peroxidase $(\mathrm{GPx})$ reduces peroxides to nonreactive products and decreases function that induces cardiac matrix remodeling [57]. Also, HOX-1 induction is absent in mice supplemented with DHA in strong contrast to $\mathrm{CD}$; here, significant induction of HOX-1 $72 \mathrm{hrs}$ after MI strongly indicates antioxidative mechanisms playing a key role in DHAmediated cardioprotection, as reported by others [44]. Therefore, our data show that DHA pretreatment reduced MI-induced GPx1- and HOX-1 expressions (Figures 5(c) and 5(d)), suggesting that DHA pretreatment induces other antioxidative mechanism potentially protecting the heart from I/R injury-induced LV remodeling.

As to this, cardiomyocytes also protect themselves against oxidative stress via mitochondrial uncoupling protein (UCP) 3, separating oxidative phosphorylation from ATP synthesis and protecting mitochondria from ROS generation
[58]. Supplementation of omega-3 fatty acids specifically induces cardiac UCP 3 expression, and overexpression protects cardiomyocytes through reduced ROS generation and apoptosis from I/R injury cardiomyocyte dysfunction and preventing cardiomyocyte death, all involved in the development of LV dysfunction [59-62]. The induced UCP 3 mRNA expression seen in the myocardium of DHA supplementation sham mice is congruent with in vitro and in vivo studies potentially preventing MI-induced oxidative stress [63-65]. The fact that UCP 3 expression decreases after I/R injury in DHA-pretreated mice is surprising, but downregulation of UCP 3 has been reported after I/R injury through the nuclear transcription factor peroxisome proliferator-activated receptor- (PPAR-) $\alpha[66,67]$. We have previously shown that pressure overload-induced hypertrophy as well as repetitive I/R is associated with a transient downregulation of PPAR- $\alpha$ and that pharmacological reactivation of PPAR- $\alpha$ as well as MHC-specific PPAR- $\alpha$ overexpression worsens contractile function, suggesting that substrate switching from fatty acid to glucose utilization in the stressed heart may preserve contractile function $[58,68,69]$. Accordingly, we show here a transient reduction of PPAR- $\alpha$ expression in both CD and DHA mice after $6 \mathrm{~h}$, but only being significant in DHAsupplemented mice compared to respective sham. This data is in accordance with previous results from the abovementioned studies but also suggests a cardioprotective effect of DHA via reduced fatty acid uptake and oxidation. We hypothesize that significant I/R injury-induced PPAR- $\alpha$ downregulation in DHA-supplemented mice results in reduced fatty acid uptake and oxidation. We further speculate that reduced $\beta$-oxidation in DHA-supplemented mice may not act as an adequate trigger for early UCP 3 upregulation at this time point. Also, within time, UCP 3 induction normalizes to sham levels in DHA-supplemented mice, potentially interconnecting transient UCP 3 downregulation to PPAR- $\alpha$ expression. 
In summary, our data suggest that DHA supplementation induces cardioprotection from myocardial ischemia and reperfusion injury through modulation of inflammatory response with early macrophage attraction but timely and attenuated remodeling. DHA seems to induce cardiomyocyte protection at least in part by transient PPAR- $\alpha$ downregulation with subsequently reduced UCP 3 expression and oxidation, diminishing the need for antioxidant mechanisms including mitochondrial function, or switch of MHCisoforms from high ATP consuming $\alpha$ - to energetically more efficient $\beta$-isoforms.

\section{Conclusions}

Cardiac dysfunction and detrimental myocardial remodeling after MI are consequences of ROS generation, inflammation, and altered energy metabolism. Various promising experimental cardioprotective interventions have targeted individual contributors of $\mathrm{I} / \mathrm{R}$ injury in animal models but have failed after translating into the clinical setting. However, MI is multifaceted and includes inflammation, ROS generation, and altered energy metabolism. Our study shows for the first time that DHA interacts with inflammation, ROS generation, LV matrix remodeling, cardiomyocyte metabolism, and contractile elements and is therefore targeting multiple mechanisms involved in cardiac I/R injury, attenuating MIinduced development of cardiac dysfunction.

\section{Data Availability}

Data will made available upon request.

\section{Conflicts of Interest}

The authors declare that there is no conflict of interest regarding the publication of this paper.

\section{Authors' Contributions}

Habicht I. and Mohsen G. contributed equally to this work. G. D. Duerr and M. Velten contributed equally to this work.

\section{References}

[1] M. Nichols, N. Townsend, R. Luengo-Fernandez et al., Statistics ECD, European Cardiovascular Disease Statistics, 2012.

[2] G. N. Levine, E. R. Bates, J. C. Blankenship et al., "2015 ACC/AHA/SCAI focused update on primary percutaneous coronary intervention for patients with ST-elevation myocardial infarction: an update of the 2011 ACCF/AHA/SCAI guideline for percutaneous coronary intervention and the 2013 ACCF/AHA guideline for the management of STelevation myocardial infarction: a report of the American College of Cardiology/American Heart Association Task Force on Clinical Practice Guidelines and the Society for Cardiovascular Angiography and Interventions," Circulation, vol. 133, no. 11, pp. 1135-1147, 2016.

[3] R. A. Kloner, S. L. Hale, W. Dai, and J. Shi, "Cardioprotection: where to from here?," Cardiovascular Drugs and Therapy, vol. 31, no. 1, pp. 53-61, 2017.
[4] R. A. Kloner, S. L. Hale, W. Dai et al., "Reduction of ischemia/reperfusion injury with bendavia, a mitochondriatargeting cytoprotective peptide," Journal of the American Heart Association, vol. 1, no. 3, article e001644, 2012.

[5] M. L. Lindsey, R. P. Iyer, M. Jung, K. Y. DeLeon-Pennell, and Y. Ma, "Matrix metalloproteinases as input and output signals for post-myocardial infarction remodeling," Journal of Molecular and Cellular Cardiology, vol. 91, pp. 134-140, 2016.

[6] L. F. Shirazi, J. Bissett, F. Romeo, and J. L. Mehta, "Role of inflammation in heart failure," Current Atherosclerosis Reports, vol. 19, no. 6, p. 27, 2017.

[7] M. Reindl, S. J. Reinstadler, H.-J. Feistritzer et al., "Relation of inflammatory markers with myocardial and microvascular injury in patients with reperfused ST-elevation myocardial infarction," European Heart Journal Acute Cardiovascular Care, vol. 6, no. 7, pp. 640-649, 2015.

[8] M. Velten, M. W. Gorr, D. J. Youtz, C. Velten, L. K. Rogers, and L. E. Wold, "Adverse perinatal environment contributes to altered cardiac development and function," American Journal of Physiology Heart and Circulatory Physiology, vol. 306, no. 9, pp. H1334-H1340, 2014.

[9] R. D. Devine, S. Bicer, P. J. Reiser, M. Velten, and L. E. Wold, "Metalloproteinase expression is altered in cardiac and skeletal muscle in cancer cachexia," American Journal of Physiology Heart and Circulatory Physiology, vol. 309, no. 4, pp. H685H691, 2015.

[10] O. Boehm, P. Knuefermann, J. Plueck et al., "TLR2 stimulation induces cardiac inflammation but not cardiac depression in vivo," Journal of Inflammation, vol. 10, no. 1, p. 33, 2013.

[11] P. Knuefermann, M. Schwederski, M. Velten et al., "Bacterial DNA induces myocardial inflammation and reduces cardiomyocyte contractility: role of toll-like receptor 9," Cardiovascular Research, vol. 78, no. 1, pp. 26-35, 2008.

[12] T. Ma, Z.-Q. Ma, X.-H. Du, Q.-S. Yu, R. Wang, and L. Liu, "Effect of valsartan on ACAT-1 and PPAR- $\gamma$ expression in intima with carotid artery endothelial balloon injury in rabbit," International Journal of Clinical and Experimental Medicine, vol. 8, no. 4, pp. 5527-5533, 2015.

[13] L. E. Wold, A. F. Ceylan-Isik, and J. Ren, "Oxidative stress and stress signaling: menace of diabetic cardiomyopathy," Acta Pharmacologica Sinica, vol. 26, no. 8, pp. 908-917, 2005.

[14] E. L. Mills and L. A. O’Neill, "Reprogramming mitochondrial metabolism in macrophages as an anti-inflammatory signal," European Journal of Immunology, vol. 46, no. 1, pp. 13-21, 2016.

[15] Y. Liu, D. Neumann, J. F. C. Glatz, and J. J. F. P. Luiken, "Molecular mechanism of lipid-induced cardiac insulin resistance and contractile dysfunction," Prostaglandins, Leukotrienes, and Essential Fatty Acids, vol. 136, pp. 131-141, 2018.

[16] D. A. Brown, S. L. Hale, C. P. Baines et al., "Reduction of early reperfusion injury with the mitochondria-targeting peptide bendavia," Journal of Cardiovascular Pharmacology and Therapeutics, vol. 19, no. 1, pp. 121-132, 2014.

[17] D. Mozaffarian and E. B. Rimm, "Fish intake, contaminants, and human health: evaluating the risks and the benefits," Journal of the American Medical Association, vol. 296, no. 15, pp. 1885-1899, 2006.

[18] B. Heydari, S. Abdullah, J. V. Pottala et al., "Effect of omega-3 acid ethyl esters on left ventricular remodeling after acute myocardial infarction: the OMEGA-REMODEL randomized clinical trial," Circulation, vol. 134, no. 5, pp. 378-391, 2016. 
[19] X. Fang, W. Cai, Q. Cheng et al., “Omega-3 PUFA attenuate mice myocardial infarction injury by emerging a protective eicosanoid pattern," Prostaglandins \& Other Lipid Mediators, vol. 139, pp. 1-9, 2018.

[20] R. Marchioli and G. Levantesi, " $n$-3 PUFAs in cardiovascular disease," International Journal of Cardiology, vol. 170, no. 2, Supplement 1, pp. S33-S38, 2013.

[21] D. Mozaffarian and S. Capewell, “United Nations' dietary policies to prevent cardiovascular disease," BMJ, vol. 343, article d5747, 2011.

[22] D. S. Siscovick, T. A. Barringer, A. M. Fretts et al., "Omega-3 polyunsaturated fatty acid (fish oil) supplementation and the prevention of clinical cardiovascular disease: a science advisory from the American Heart Association," Circulation, vol. 135, no. 15, pp. e867-e884, 2017.

[23] M. Burban, G. Meyer, A. Olland et al., “An intravenous bolus of Epa: Dha 6: 1 protects against myocardial ischemiareperfusion-induced shock," Shock, vol. 46, no. 5, pp. 549$556,2016$.

[24] N. Madingou, K. Gilbert, L. Tomaro et al., "Comparison of the effects of EPA and DHA alone or in combination in a murine model of myocardial infarction," Prostaglandins, Leukotrienes, and Essential Fatty Acids, vol. 111, pp. 11-16, 2016.

[25] R. Wang, Q. Chai, T. Lu, and H.-C. Lee, “Activation of vascular BK channels by docosahexaenoic acid is dependent on cytochrome P450 epoxygenase activity," Cardiovascular Research, vol. 90, no. 2, pp. 344-352, 2011.

[26] G. G. Abdukeyum, A. J. Owen, T. A. Larkin, and P. L. McLennan, "Up-regulation of mitochondrial antioxidant superoxide dismutase underpins persistent cardiac nutritionalpreconditioning by long chain n-3 polyunsaturated fatty acids in the rat," Journal of Clinical Medicine, vol. 5, no. 3, p. 32, 2016.

[27] S. Zeghichi-Hamri, M. de Lorgeril, P. Salen et al., "Protective effect of dietary n-3 polyunsaturated fatty acids on myocardial resistance to ischemia-reperfusion injury in rats," Nutrition Research, vol. 30, no. 12, pp. 849-857, 2010.

[28] S. Pepe and P. L. McLennan, "Cardiac membrane fatty acid composition modulates myocardial oxygen consumption and postischemic recovery of contractile function," Circulation, vol. 105, no. 19, pp. 2303-2308, 2002.

[29] D. J. Hausenloy and D. M. Yellon, "Myocardial ischemiareperfusion injury: a neglected therapeutic target," The Journal of Clinical Investigation, vol. 123, no. 1, pp. 92-100, 2013.

[30] T. O. Nossuli, V. Lakshminarayanan, G. Baumgarten et al., "A chronic mouse model of myocardial ischemia-reperfusion: essential in cytokine studies," American Journal of Physiology Heart and Circulatory Physiology, vol. 278, no. 4, pp. H1049H1055, 2000.

[31] L. K. Rogers, C. J. Valentine, M. Pennell et al., "Maternal docosahexaenoic acid supplementation decreases lung inflammation in hyperoxia-exposed newborn mice," The Journal of Nutrition, vol. 141, no. 2, pp. 214-222, 2011.

[32] M. Velten, R. D. Britt, K. M. Heyob, T. E. Tipple, and L. K. Rogers, "Maternal dietary docosahexaenoic acid supplementation attenuates fetal growth restriction and enhances pulmonary function in a newborn mouse model of perinatal inflammation," The Journal of Nutrition, vol. 144, no. 3, pp. 258-266, 2014.

[33] M. Ali, K. M. Heyob, M. Velten, T. E. Tipple, and L. K. Rogers, "DHA suppresses chronic apoptosis in the lung caused by perinatal inflammation," American Journal of Physiology Lung Cellular and Molecular Physiology, vol. 309, no. 5, pp. L441L448, 2015.

[34] B. M. Anderson and D. W. L. Ma, "Are all n-3 polyunsaturated fatty acids created equal?," Lipids in Health and Disease, vol. 8, no. 1, article 33, 2009.

[35] P. Pacher, T. Nagayama, P. Mukhopadhyay, S. Bátkai, and D. A. Kass, "Measurement of cardiac function using pressure-volume conductance catheter technique in mice and rats," Nature Protocols, vol. 3, no. 9, pp. 1422-1434, 2008.

[36] N. G. Frangogiannis, J. L. Perrard, L. H. Mendoza et al., "Stem cell factor induction is associated with mast cell accumulation after canine myocardial ischemia and reperfusion," Circulation, vol. 98, no. 7, pp. 687-698, 1998.

[37] C. Weisheit, Y. Zhang, A. Faron et al., "Ly6C(low) and not Ly6C(high) macrophages accumulate first in the heart in a model of murine pressure-overload," PLoS One, vol. 9, no. 11, article e112710, 2014.

[38] S. A. Bustin, V. Benes, J. A. Garson et al., "The MIQE guidelines: minimum information for publication of quantitative real-time PCR experiments," Clinical Chemistry, vol. 55, no. 4, pp. 611-622, 2009.

[39] T. A. Mori, "Marine OMEGA-3 fatty acids in the prevention of cardiovascular disease," Fitoterapia, vol. 123, pp. 51-58, 2017.

[40] D. D. Alexander, P. E. Miller, M. E. Van Elswyk, C. N. Kuratko, and L. C. Bylsma, "A meta-analysis of randomized controlled trials and prospective cohort studies of eicosapentaenoic and docosahexaenoic long-chain omega-3 fatty acids and coronary heart disease risk," Mayo Clinic Proceedings, vol. 92, no. 1, pp. 15-29, 2017.

[41] S. Khadge, J. G. Sharp, G. M. Thiele et al., "Dietary omega-3 and omega- 6 polyunsaturated fatty acids modulate hepatic pathology," The Journal of Nutritional Biochemistry, vol. 52, pp. 92-102, 2018.

[42] L. Liu, Q. Hu, H. Wu et al., "Dietary DHA/EPA Ratio Changes Fatty Acid Composition and Attenuates Diet- Induced Accumulation of Lipid in the Liver of $\mathrm{ApoE}^{-/-}$Mice," Oxidative Medicine and Cellular Longevity, vol. 2018, Article ID 6256802, 12 pages, 2018.

[43] A. M. Deschamps, E. Murphy, and J. Sun, "Estrogen receptor activation and cardioprotection in ischemia reperfusion injury," Trends in Cardiovascular Medicine, vol. 20, no. 3, pp. 73-78, 2010.

[44] G. D. Duerr, J. C. Heinemann, C. Gestrich et al., "Impaired border zone formation and adverse remodeling after reperfused myocardial infarction in cannabinoid CB2 receptor deficient mice," Life Sciences, vol. 138, pp. 8-17, 2015.

[45] T. Hilbert, P. Markowski, S. Frede et al., "Synthetic CpG oligonucleotides induce a genetic profile ameliorating murine myocardial I/R injury," Journal of Cellular and Molecular Medicine, vol. 22, no. 7, pp. 3397-3407, 2018.

[46] S.-C. Kim, S. Wu, X. Fang et al., "Postconditioning with a CpG containing oligodeoxynucleotide ameliorates myocardial infarction in a murine closed-chest model," Life Sciences, vol. 119, no. 1-2, pp. 1-8, 2014.

[47] G. D. Duerr, D. Dewald, E. J. Schmitz et al., "Metallothioneins 1 and 2 modulate inflammation and support remodeling in ischemic cardiomyopathy in mice," Mediators of Inflammation, vol. 2016, Article ID 7174127, 13 pages, 2016.

[48] G. D. Duerr, J. C. Heinemann, G. Suchan et al., "The endocannabinoid-CB2 receptor axis protects the ischemic 
heart at the early stage of cardiomyopathy," Basic Research in Cardiology, vol. 109, no. 4, p. 425, 2014.

[49] M. Velten, K. M. Heyob, L. E. Wold, and L. K. Rogers, "Perinatal inflammation induces sex-related differences in cardiovascular morbidities in mice," American Journal of PhysiologyHeart and Circulatory Physiology, vol. 314, no. 3, pp. H573H579, 2018.

[50] M. Velten, G. D. Duerr, T. Pessies et al., "Priming with synthetic oligonucleotides attenuates pressure overload-induced inflammation and cardiac hypertrophy in mice," Cardiovascular Research, vol. 96, no. 3, pp. 422-432, 2012.

[51] E. Carniel, M. R. G. Taylor, G. Sinagra et al., “Alpha-myosin heavy chain: a sarcomeric gene associated with dilated and hypertrophic phenotypes of cardiomyopathy," Circulation, vol. 112, no. 1, pp. 54-59, 2005.

[52] M. Kamisago, J. P. Schmitt, D. McNamara, C. Seidman, and J. G. Seidman, "Sarcomere protein gene mutations and inherited heart disease: a $\beta$-cardiac myosin heavy chain mutation causing endocardial fibroelastosis and heart failure," Novartis Foundation Symposia, vol. 274, pp. 176-189, 2006.

[53] J. Fang, Y. Li, K. Zhou, Y. Hua, C. Wang, and D. Mu, "Antithetical regulation of $\alpha$-myosin heavy chain between fetal and adult heart failure though shuttling of HDAC5 regulating YY-1 function," Cardiovascular Toxicology, vol. 15, no. 2, pp. 147-156, 2015.

[54] L. E. Wold, Z. Ying, K. R. Hutchinson et al., "Cardiovascular remodeling in response to long-term exposure to fine particulate matter air pollution," Circulation Heart Failure, vol. 5, no. 4, pp. 452-461, 2012.

[55] D. Moris, M. Spartalis, E. Spartalis et al., "The role of reactive oxygen species in the pathophysiology of cardiovascular diseases and the clinical significance of myocardial redox," Annals of Translational Medicine, vol. 5, no. 16, p. 326, 2017.

[56] D. M. Muntean, A. Sturza, M. D. Dănilă, C. Borza, O. M. Duicu, and C. Mornoș, "The role of mitochondrial reactive oxygen species in cardiovascular injury and protective strategies," Oxidative Medicine and Cellular Longevity, vol. 2016, Article ID 8254942, 19 pages, 2016.

[57] M. A. Forgione, A. Cap, R. Liao et al., "Heterozygous cellular glutathione peroxidase deficiency in the mouse: abnormalities in vascular and cardiac function and structure," Circulation, vol. 106, no. 9, pp. 1154-1158, 2002.

[58] O. Dewald, S. Sharma, J. Adrogue et al., "Downregulation of peroxisome proliferator-activated receptor-alpha gene expression in a mouse model of ischemic cardiomyopathy is dependent on reactive oxygen species and prevents lipotoxicity," Circulation, vol. 112, no. 3, pp. 407-415, 2005.

[59] J. P. Brennan, R. Southworth, R. A. Medina, S. M. Davidson, M. R. Duchen, and M. J. Shattock, "Mitochondrial uncoupling, with low concentration FCCP, induces ROS-dependent cardioprotection independent of KATP channel activation," Cardiovascular Research, vol. 72, no. 2, pp. 313-321, 2006.

[60] S. M. Nadtochiy, A. J. Tompkins, and P. S. Brookes, "Different mechanisms of mitochondrial proton leak in ischaemia/reperfusion injury and preconditioning: implications for pathology and cardioprotection," The Biochemical Journal, vol. 395, no. 3, pp. 611-618, 2006.

[61] K. S. Edwards, S. Ashraf, T. M. Lomax et al., "Uncoupling protein 3 deficiency impairs myocardial fatty acid oxidation and contractile recovery following ischemia/reperfusion," Basic Research in Cardiology, vol. 113, no. 6, p. 47, 2018.
[62] M. E. Young, S. Patil, J. Ying et al., "Uncoupling protein 3 transcription is regulated by peroxisome proliferator-activated receptor (alpha) in the adult rodent heart," The FASEB Journal, vol. 15, no. 3, pp. 833-845, 2001.

[63] T. Leger, K. Azarnoush, A. Traoré et al., “Antioxidant and cardioprotective effects of EPA on early low-severity sepsis through UCP3 and SIRT3 upholding of the mitochondrial redox potential," Oxidative Medicine and Cellular Longevity, vol. 2019, Article ID 9710352, 21 pages, 2019.

[64] M.-S. Lee, I.-H. Kim, and Y. Kim, "Effects of eicosapentaenoic acid and docosahexaenoic acid on uncoupling protein 3 gene expression in $\mathrm{C}(2) \mathrm{C}(12)$ muscle cells," Nutrients, vol. 5, no. 5 , pp. 1660-1671, 2013.

[65] J. Himms-Hagen and M. E. Harper, "Physiological role of UCP3 may be export of fatty acids from mitochondria when fatty acid oxidation predominates: an hypothesis," Experimental Biology and Medicine, vol. 226, no. 2, pp. 78-84, 2016.

[66] P. M. Barger and D. P. Kelly, "PPAR signaling in the control of cardiac energy metabolism," Trends in Cardiovascular Medicine, vol. 10, no. 6, pp. 238-245, 2000.

[67] A. K. Rines, H.-C. Chang, R. Wu et al., "Snf1-related kinase improves cardiac mitochondrial efficiency and decreases mitochondrial uncoupling," Nature Communications, vol. 8, no. 1, article 14095, 2017.

[68] G. D. Duerr, J. C. Heinemann, V. Arnoldi et al., "Cardiomyocyte specific peroxisome proliferator-activated receptor- $\alpha$ overexpression leads to irreversible damage in ischemic murine heart," Life Sciences, vol. 102, no. 2, pp. 88-97, 2014.

[69] M. E. Young, F. A. Laws, G. W. Goodwin, and H. Taegtmeyer, "Reactivation of peroxisome proliferator-activated receptor alpha is associated with contractile dysfunction in hypertrophied rat heart," Journal of Biological Chemistry, vol. 276, no. 48 , pp. 44390-44395, 2001. 